\title{
Redefined clinical spectra of diabetic foot syndrome
}

This article was published in the following Dove Press journal: Vascular Health and Risk Management

\author{
Nawaf J Shatnawi' \\ Nabil A Al-Zoubi' \\ Hasan Hawamdeh ${ }^{2}$ \\ Yousef S Khader ${ }^{3}$ \\ Abd El-Karim Omari ${ }^{1}$ \\ Muhammad R Khammash' \\ 'Department of Surgery, Jordan \\ University of Science and Technology, \\ Irbid, Jordan; ${ }^{2}$ Department of Basic \\ Medical Science, Faculty of Medicine, \\ Hashemite University, Zarqa, Jordan; \\ ${ }^{3}$ Department of Community Medicine, \\ Public Health and Family Medicine, \\ Jordan University of Science and \\ Technology, Irbid, Jordan
}

Purpose: The aim of this study was to present the redefined clinical spectra of diabetic foot syndrome (RCS-DFS) and determine whether the RCS-DFS can be used to predict amputations. Patients and methods: This is a retrospective study of type 2 diabetic patients referred with DFS for management at King Abdullah University Hospital (KAUH) between January 2014 and December 2015. Data collection form and diabetic foot (DF) characteristic chart were used to document the following: demographic data, diabetes-related parameters, DF characteristics, surgical interventions and amputations. The predominant clinical presentations of DF problems (ulcer, sepsis or gangrene) were integrated with the clinical criteria for diabetic foot infection (DFI) diagnosis and classification of Infectious Diseases Association of America (IDSA)/International Working Group on Diabetic Foot (IWGDF) to redefine the clinical spectra of DFS. Related risk characteristics and amputation rate at all levels were compared between the three RCS.

Results: In this study, there were 95 (47.0\%) septic DFS (SDFS) patients, 65 (32.2\%) ulcerative DFS (UDFS) patients and 42 (20.8\%) gangrenous DFS (GDFS) patients. Poor glycemic control (HbA1c $>7.5 \%$ ), hypertension, history of the same foot problems, duration of symptoms, revascularizations and ischemic severity were significantly different between the three RCS. UDFS had the highest rate of limb salvage without amputations (70.8\%). GDFS had the highest rate for final toe amputations (52.4\%) and major amputations (23.8\%). Final minor amputation rate was around $20 \%$ for both SDFS and GDFS.

Conclusion: Redefining DFS into ulcerative, septic and gangrenous by integration of the predominant clinical presentation and the clinical criteria for DFI diagnosis and classification of IDSA/IWGDF showed significant differences in amputation rate. Therefore, it can be used clinically to categorize patients with DFS to predict amputations and to help in planning their management. Further prospective studies are suggested to validate these results.

Keywords: diabetes mellitus, classification, diabetic foot syndrome, amputations

\section{Introduction}

Diabetic foot (DF) problems are common, costly and disabling with high rate of recurrence, amputations and mortality. ${ }^{1-3}$ They result from interaction of several diabetes-related components in variable proportions of severity (neuropathy, ischemia and infections). ${ }^{2,4-6}$ These problems are collectively known as DF syndrome (DFS)., 3,78 However, the WHO defines DFS as an ulcer of the foot of diabetic patients distal to the malleoli associated with diabetes-related complications. ${ }^{9}$

Because the presentations and outcomes of DFS are diverse, several DF classification systems have been proposed. Wagner' ${ }^{10}$ classification system is a clinical description of DF problems, while the University of Texas (UT) classification system
Department of Surgery, Jordan University of Science and Technology, P.O. Box 3030, Irbid 22110, Jordan

Tel +962795576267

Email nshatnawi@yahoo.com 
is an integration of infections and ischemia as stages (A-D) with Wagner's grades $0-3 .{ }^{11,12}$ Further attempts to incorporate important pathogenic and outcome-related parameters, such as perfusion, extent of ulcer (size), ulcer depth, infection and sensation were proposed, as in the perfusion, extent, depth, infection and sensation (PEDIS) classification system by the International Working Group on Diabetic Foot (IWGDF). ${ }^{13}$ The severity of DF infections (DFIs) was brought into focus, where the association of Infectious Diseases Association of America (IDSA) and the IWGDF proposed independently a strict clinical criteria for diagnosis and classification of DFIs, which are classified as mild, moderate and severe infection. ${ }^{14,15}$ King's classification system categorized the clinical spectra of DF problems into stages (1-5): normal foot, foot at risk, ulcerative DF, infected (septic) DF and necrotic (gangrenous) DF. ${ }^{16}$ Classification of DFS is needed to facilitate communication between health care providers and researchers to provide appropriate patient care. Redefinition and classifications are driven by low level of satisfaction and are encouraged by increasing level of understanding pathogenic components of DFS. ${ }^{11-13,17}$

In this study, we integrated the predominant clinical presentations of DF problems (ulcer, sepsis or gangrene) with the clinical criteria for DFI diagnosis and classification of IDSA/IWGDF ${ }^{14}$ to redefine the clinical spectra of DFS (RCS-DFS). The aim of this study was to present the RCSDFS and determine its ability to predict amputations among referred patients with DFS for hospital management at King Abdullah University hospital (KAUH).

\section{Patients and methods}

This is a retrospective study of 202 consecutive type 2 diabetic patients, referred with DFS for management at KAUH during the period from January 2014 to December 2015. $\mathrm{KAUH}$ is the main teaching and referral hospital in northern part of Jordan. Patients with chronic limb ischemia without tissue loss were excluded. Patients with DFS are managed according to an updated protocol consistent with the international guidelines. ${ }^{15,18}$ The management of these patients is carried out under the care of vascular surgeon according to KAUH policies, who might request additional consultations when needed.

The RCS-DFS is defined as follows: chronic unhealed DF ulcer with/without mild infections was classified as ulcerative DFS (UDFS); clinical evidence of moderate or severe DFI with/without tissue loss (ulcer, gangrene) was classified as septic DFS (SDFS); finally, foot gangrene at presentation in diabetic with/without mild infection was classified as gangrenous DFS (GDFS). Infections are classified into mild (superficial and limited in size and depth), moderate (deeper or more extensive) or severe (accompanied by systemic signs or metabolic perturbations) according to "Infectious Diseases Society of America Clinical Practice Guideline for the Diagnosis and Treatment of DFIs".

Admitted patients were assessed for comorbidities including smoking, hypertension, cardiac diseases, chronic renal impairments/hemodialysis, acute renal impairments, stroke and history of feet problems. Other data were collected on diabetes-related parameters (type of diabetes, duration of diabetes, glycemic control and the modality of control of hyperglycemia) and DF characteristics: ulcer (site and depth), gangrene (extent/site), clinical evidence of infection and severity (Lipsky et $\mathrm{al}^{15}$ ), presence of neuropathy (10 g monofilament test), severity of ischemia (symptoms, physical examination, Ankle Brachial Pressure Index [ABI $])^{19}$ and RCS-DFS (UDFS, SDFS and GDFS).

A structured customized DF data collection form and DF characteristic chart were used to document the following: demographic data, comorbidities, diabetes-related parameters, DF characteristics, surgical interventions (debridement, incision and drainage) and amputation level. The DF characteristic chart was used to document DF characteristics: foot perfusion, foot sensation, foot ulcer depth, infection and site of tissue lose (ulcer or gangrene).

For the purpose of this study, DF problems were categorized according to Wagner's classification of DF: no ulcers $=$ grade 0 ; full-thickness skin ulcer $=$ grade 1 ; ulcer penetrating to muscle, tendon or joint capsule $=$ grade 2 ; deep ulcer reaching bone or joint with the evidence of deep-seated abscess or osteomyelitis = grade 3 ; limited gangrene not extending proximal to metatarsal head = grade 4 ; and gangrene extending proximal to metatarsal head $=$ grade 5 .

Severe ischemia was defined as ABI of $\leq 0.5$, mild $/$ moderate ischemia was defined as ABI of 0.51-0.9 and no ischemia was defined as ABI of $>0.9 .{ }^{19}$

Amputation is defined as the removal of extremity tissue that involves bone resections. Toe amputation refers to single or multiple toe amputation excluding big toe amputation. Minor amputation refers to amputation involving the foot that spares an intact heel. Big toe amputations are considered as minor amputations. Major amputation is defined as amputation that interferes with the heel. ${ }^{20}$ Final amputation refers to the end result of foot problem whether there is no amputation at any level or there is the level with healed stump.

The medical records and hospital databases were used to retrieve data relevant to our study. The ethical approval was 
obtained from the institutional review board (IRB) at Jordan University of Science and Technology. The IRB did not require the patients' consent to review their medical records because their information was abstracted by the treating physician. Every effort was made to protect the patient data confidentiality. Statistical analysis was performed using SPSS version 22. Frequencies and percentages were calculated for different variables. Data were analyzed using the chi-squared test. The difference was considered significant if $P$-value was $\leq 0.05$.

\section{Results}

A total of 202 type 2 diabetic patients with DFS were included in the study. The distribution of DFS spectra was $65(32.2 \%)$ UDFS patients, 95 (47.0\%) SDFS patients and 42 (20.8\%) GDFS patients according to RCS-DFS.
The distribution of patients' related characteristics and diabetes-related parameters according to RCS-DFS is summarized in Table 1. The prevalence of poor glycemic control (HbAlc $>7.5 \%$ ), hypertension, history of the same foot problems, duration of symptoms and revascularizations differed significantly according to RCS-DFS. The prevalence of foot characteristics, main risk factors and the final amputation rate of Wagner's grades are summarized in Table 2. There are no significant differences related to distribution of diabetic neuropathy (DPN) in RCS-DFS. The prevalence of ischemia $(\mathrm{ABI} \leq 0.9)$ was the highest in patients with GDFS $(92.9 \%)$, followed by UDFS $(61.5 \%)$, and the lowest prevalence of ischemia was found in patients with SDFS $(38.9 \%$; $P$-value $<0.001)$. Severe ischemia showed higher prevalence $(59.5 \%)$ for patients with GDFS compared to patients with SDFS

Table I The relation of the RCS-DFS to distribution of patient (demographic and health)-related risk characteristics

\begin{tabular}{|c|c|c|c|c|c|}
\hline \multirow{2}{*}{$\begin{array}{l}\text { Patient (demographic and health)- } \\
\text { related risk characteristics }\end{array}$} & \multicolumn{3}{|c|}{ Spectra of DFS } & \multirow[t]{2}{*}{$P$-value } & \multirow[t]{2}{*}{ Total, N (\%) } \\
\hline & GDFS, n (\%) & UDFS, n (\%) & SDFS, n (\%) & & \\
\hline \multicolumn{6}{|l|}{ Age (years) } \\
\hline$\leq 55$ & $14(33.3)$ & $23(35.4)$ & $31(32.6)$ & 0.935 & $68(33.7)$ \\
\hline$>55$ & $28(66.7)$ & $42(64.6)$ & $64(67.4)$ & & $134(66.3)$ \\
\hline \multicolumn{6}{|l|}{ Gender } \\
\hline Male & $25(59.5)$ & $48(73.8)$ & $66(69.5)$ & 0.29 & $139(68.8)$ \\
\hline Female & $17(40.5)$ & $17(26.2)$ & $29(30.5)$ & & $63(31.2)$ \\
\hline \multicolumn{6}{|l|}{ BMI $\left(\mathbf{k g} / \mathbf{m}^{2}\right)$} \\
\hline$\leq 25$ & $27(64.3)$ & $36(55.4)$ & $45(47.4)$ & 0.174 & $108(53.5)$ \\
\hline$>25$ & $15(35.7)$ & $29(44.6)$ & $50(52.6)$ & & $94(46.5)$ \\
\hline \multicolumn{6}{|l|}{ Diabetic duration (years) } \\
\hline$\leq 10$ & $12(28.6)$ & $21(32.3)$ & $29(30.5)$ & 0.919 & $62(30.7)$ \\
\hline$>10$ & $30(7 \mid .4)$ & 44 (67.7) & $66(69.5)$ & & $140(69.3)$ \\
\hline \multicolumn{6}{|l|}{ HbAlc (\%) } \\
\hline$\leq 7.5$ & $8(19)$ & $29(44.6)$ & $28(29.5)$ & 0.016 & $65(32.2)$ \\
\hline$>7.5$ & $34(8 I)$ & $36(55.4)$ & $67(70.5)$ & & $137(67.8)$ \\
\hline \multicolumn{6}{|l|}{ ESR } \\
\hline$\leq 48$ & $23(54.8)$ & $29(44.6)$ & $44(46.3)$ & 0.560 & $96(47.5)$ \\
\hline$>48$ & $19(45.2)$ & $36(55.4)$ & $51(53.7)$ & & $106(52.5)$ \\
\hline \multicolumn{6}{|l|}{ Modality of control of hyperglycemia } \\
\hline Oral & $22(52.4)$ & $34(52.3)$ & $47(49.5)$ & 0.921 & $103(54)$ \\
\hline Insulin & $20(47.6)$ & 31 (47.7) & $48(50.5)$ & & $93(46)$ \\
\hline \multicolumn{6}{|l|}{ Comborbidities, risk factors, history } \\
\hline Smoking & $22(52.4)$ & $39(60.0)$ & $46(48.4)$ & 0.353 & $107(53)$ \\
\hline Hypertension & $32(76.2)$ & $35(53.8)$ & $54(56.8)$ & 0.05 & $12 \mid(59.9)$ \\
\hline Cardiac disease & $15(35.7)$ & $27(41.5)$ & $34(35.8)$ & 0.731 & $76(37.6)$ \\
\hline Chronic renal impairments & $4(9.5)$ & $10(15.4)$ & $22(23.2)$ & 0.130 & $36(17.8)$ \\
\hline History of stroke & $6(14.3)$ & $3(4.6)$ & $8(8.4)$ & 0.213 & $17(8.4)$ \\
\hline History of foot problems & $27(64.3)$ & $23(35.4)$ & $35(36.8)$ & 0.005 & $85(42.1)$ \\
\hline History of problems of other foot & $22(52.4)$ & $27(4 I .5)$ & $34(35.8)$ & 0.190 & $83(41.3)$ \\
\hline \multicolumn{6}{|l|}{ Symptom duration (weeks) } \\
\hline$\leq 4$ & $33(78.6)$ & $24(36.9)$ & $70(73.7)$ & 0.000 & $127(62.9)$ \\
\hline$>4$ & $9(21.4)$ & $4 I(63.1)$ & $25(26.3)$ & & $75(37.1)$ \\
\hline \multicolumn{6}{|l|}{ Primary revascularization } \\
\hline No & $8(19)$ & $29(44.6)$ & $66(69.5)$ & 0.000 & $103(5 \mathrm{I})$ \\
\hline Yes & $34(8 I)$ & $36(55.4)$ & $29(30.5)$ & & $99(49)$ \\
\hline
\end{tabular}

Abbreviations: BMI, body mass index; DFS, diabetic foot syndrome; ESR, erythrocyte sedimentation rate; GDFS, gangrenous DFS; RCS-DFS, redefined clinical spectra of DFS; SDFS, septic DFS; UDFS, ulcerative DFS. 
Table 2 The amputation of the RCS-DFS to distributions of foot-related risk characteristics and final amputation

\begin{tabular}{|c|c|c|c|c|c|}
\hline \multirow{2}{*}{$\begin{array}{l}\text { Foot-related risk } \\
\text { characteristics }\end{array}$} & \multicolumn{3}{|c|}{ Spectra of DFS } & \multirow[t]{2}{*}{$P$-value } & \multirow[t]{2}{*}{ Total, N (\%) } \\
\hline & GDFS, n (\%) & UDFS, n (\%) & SDFS, n (\%) & & \\
\hline \multicolumn{6}{|l|}{ Gangrene } \\
\hline No & $0(0)$ & $65(100)$ & $65(68.4)$ & 0.000 & $130(64.4)$ \\
\hline Yes & $42(100)$ & $0(0)$ & $30(31.6)$ & & $72(35.6)$ \\
\hline \multicolumn{6}{|l|}{ Ulcer } \\
\hline No & $42(100)$ & $0(0)$ & $52(54.7)$ & 0.000 & $94(46.5)$ \\
\hline Yes & $0(0)$ & $65(100)$ & $43(45.3)$ & & $108(53.5)$ \\
\hline \multicolumn{6}{|l|}{ Ischemic grade } \\
\hline No ischemia & $3(7.1)$ & $25(38.4)$ & $58(61.1)$ & 0.000 & $86(42.6)$ \\
\hline$A B I \geq 0.5 I$ & $14(33.3)$ & $24(36.9)$ & $18(18.9)$ & & $56(27.7)$ \\
\hline$A B I<0.5 I$ & $25(59.5)$ & $16(24.6)$ & $19(20.0)$ & & $60(29.7)$ \\
\hline \multicolumn{6}{|l|}{ Infection } \\
\hline No clinical evidence & $23(54.8)$ & $33(50.8)$ & $0(0)$ & 0.000 & $56(27.7)$ \\
\hline Mild (IWGDF) & $19(45.2)$ & $32(49.2)$ & $0(0)$ & & $5 I(25.2)$ \\
\hline Moderate (IWGDF) & $0(0)$ & $0(0)$ & $83(87.4)$ & & $83(4 I . I)$ \\
\hline Severe (IWGDF) & $0(0)$ & $0(0)$ & $12(12.6)$ & & $12(5.9)$ \\
\hline \multicolumn{6}{|l|}{ Neuropathy } \\
\hline No & $23(54.8)$ & $26(40)$ & $35(36.8)$ & 0.000 & $84(4 I .6)$ \\
\hline Yes & $19(45.2)$ & $39(60)$ & $60(63.2)$ & & $118(58.4)$ \\
\hline \multicolumn{6}{|l|}{ Ischemic gangrene } \\
\hline No & $3(7.1)$ & $65(100)$ & $84(88.4)$ & 0.000 & $152(75.2)$ \\
\hline Yes & $39(92.9)$ & $0(0)$ & II (II.6) & & $50(24.8)$ \\
\hline \multicolumn{6}{|l|}{ Ischemic ulcer } \\
\hline No & $42(100)$ & $25(38.4)$ & $79(83.2)$ & 0.000 & $146(72.2)$ \\
\hline Yes & $0(0)$ & $40(61.5)$ & $16(16.8)$ & & $56(27.8)$ \\
\hline \multicolumn{6}{|l|}{ Components } \\
\hline One component & $13(31.0)$ & $21(48.8)$ & $9(9.5)$ & 0.001 & $43(2 \mid .3)$ \\
\hline Two components & $24(57.4)$ & $42(64.6)$ & $76(80.0)$ & & $142(70.3)$ \\
\hline Three components & $5(11.9)$ & $2(3.1)$ & $10(10.5)$ & & $17(8.4)$ \\
\hline \multicolumn{6}{|l|}{ Wagner's grade } \\
\hline Grade 2 & $0(0)$ & $57(87.7)$ & $13(13.7)$ & 0.000 & 70 (34.7) \\
\hline Grade 3 & $0(0)$ & $8(12.3)$ & $52(54.7)$ & & $60(29.7)$ \\
\hline Grade 4 & $42(100)$ & $0(0)$ & $30(31.6)$ & & $72(35.6)$ \\
\hline \multicolumn{6}{|l|}{ Final amputation } \\
\hline No amputation & I (2.4) & $46(70.8)$ & 34 (37.9) & 0.000 & $81(40.1)$ \\
\hline Toe amputation & $22(52.4)$ & $13(20.0)$ & $28(29.5)$ & & $62(30.7)$ \\
\hline Minor amputation & $9(21.4)$ & $3(4.6)$ & $20(2 I .1)$ & & $32(15.8)$ \\
\hline Major amputation & $10(21.4)$ & $3(4.6)$ & $13(13.7)$ & & $26(12.9)$ \\
\hline
\end{tabular}

Abbreviations: ABI, Ankle Brachial Pressure Index; DFS, diabetic foot syndrome; GDFS, gangrenous DFS; IWGDF, International Working Group on Diabetic Foot; RCSDFS, redefined clinical spectra of DFS; SDFS, septic DFS; UDFS, ulcerative DFS.

(20\%; $P$-value $<0.001)$. Gangrene was found in 72 patients (35.6\% of all DFS). Gangrene as part of GDFS was found in 42 patients ( $58.3 \%$ of all gangrene) and as part of SDFS was found in 30 patients ( $41.7 \%$ of all gangrene). Moderate infection was found in $87.4 \%$ and severe sepsis in $12.6 \%$ of SDFS. Both GDFS and UDFS had a prevalence of mild infection of $42.2 \%$ and $49.2 \%$, respectively.

Ulcers were found in 108 (53.5\%) patients, where 65 (60.2\% of all ulcers) patients had UDFS and 43 (39.8\% of all ulcers) patients had SDFS.

All patients with GDFS had gangrene at presentation with Wagner's grade 4, none had grade 5. Most patients with
UDFS had Wagner's grade $2(87.7 \%$ ), while $54.7 \%$ and $31.6 \%$ of SDFS had Wagner's grade 3 and 4, respectively.

In this study, toe amputations were performed in $30.7 \%$, minor amputations in $15.8 \%$ and major amputations in $12.9 \%$, while only $40.1 \%$ of all DFSs had limb salvage with no amputations at any levels. The rate of final amputation in relation to RCS-DFS showed high rate for toe amputations (52.4\%) and major amputations $(23.8 \%)$ in association with GDFS, while the rate of minor amputation was around $21 \%$ for both GDFS and SDFS. UDFS had the highest rate of limb salvage with no amputations at any level (70.8\%; $P$-value $=0.000)$. Amputation rates for all levels among 
RCS-DFS attained significant difference. Amputation rates at different levels in relation to RCS-DFS are listed in Table 3.

\section{Discussion}

The prevalence of SDFS, UDFS and GDFS was 47\% 32.2\% and $20.8 \%$, respectively. The main defining features of these RCS-DFS were infection severities and types of tissue loss (ulcer or gangrene). In fact, ulcer, infection and gangrene are the recognized clinical problems in practice. ${ }^{5}$ Nather et $\mathrm{al}^{21}$ reported infections in $39.6 \%$, gangrene in $31.7 \%$ and ulcers in $27 \%$ of DF problems treated at hospital. Although Wagner's classification recognized ulcer, infections and gangrene as different grades of DF problems, ulcer depth alone represents Wagner's grade 0-2, while deep ulcer reaching the bone with deep-seated infection/osteomyelitis constitutes grade 3 , and gangrene constitutes grades $4-5 .{ }^{10}$ On the other hand, King's classification recognized them as different stages of DF problem with increasing severity. However, the severity of infection was not defined. ${ }^{16}$

Patients with UDFS had longer duration of symptoms prior to referral, and patients with GDFS had higher prevalence of poor glycemic control (HbAlc $>7.5 \%$ ), history of hypertension, history of same foot problems and higher rate of primary revascularization. On the other hand, age, gender and body mass index were not significantly different among the RCS-DFS. An increased risk was associated with DPN, peripheral artery disease (PAD), past history of foot problems, longer duration of diabetes, male gender, old age, poor glycemic control and comorbidities. ${ }^{2,5,22}$ The prevalence of DPN was $58 \%$ in this study group. However, the prevalence of DPN showed no significant difference between RCS-DFS categories. DPN is a well-recognized component responsible for the increased risk of DF problems especially ulcers. ${ }^{2,4,5,23}$
Most patients with septic RCS-DFS had two or more components $(90.5 \%)$, while patients with UDFS and GDFS had comparable prevalence of two or more components $(P$-value 0.001). This finding is consistent with others, as DFSs are more likely to result from interaction of two or more components in variable proportions. ${ }^{1,2,24}$

Ischemia prevalence $(\mathrm{ABI} \leq 0.9)$ was $57.4 \%$ of DFS in this study. Variable ischemic prevalence rates had been reported among patients with DFS. ${ }^{8,12,25}$ Nearly $50 \%$ of DFS had ischemia (UT stage C-D). ${ }^{19}$ Ischemic prevalence rates differed significantly according to the category of RCS-DFS. Ischemia is an important component associated with the development of DFS with consequent poor outcome in general.,11,19,23-27 PAD is two to three times more common in diabetics compared to nondiabetics. ${ }^{28,29}$ However, patients with DFS have higher risk for amputation compared to patients with PAD whether they have diabetes or not. ${ }^{3}$

Severe ischemia as defined by ABI $(\leq 0.5)$ was found in nearly $60 \%$ of GDFS and in $24.6 \%$ of UDFS ( $P$-value $\leq 0.001)$. PAD tends to be severe in diabetic patients with higher prevalence of leg vessel involvement. ${ }^{28-30}$ In fact, ischemia is well recognized in the pathway to DF ulcer with poor healing and poor overall outcome. , 11,19,25,27 $^{4}$

The prevalence of ischemic gangrene revealed significant difference among the RCS-DFS. The prevalence of gangrene was $31.6 \%$ in SDFS; nearly $11 \%$ of SDFS-associated gangrene were ischemic, while most of the GDFS-associated gangrene was ischemic $(92.9 \% ; P$-value $\leq 0.001)$. Severe ischemia might progress to rest pain and tissue loss, ${ }^{29}$ while deep-seated infections might be associated with the development of tissue destruction and gangrene even in the presence of mild ischemia. ${ }^{24}$ Severe DFIs even without relevant hemodynamic atherosclerotic lesions can result in

Table 3 The relation of the RCS-DFS to amputation at all levels

\begin{tabular}{|c|c|c|c|c|c|}
\hline \multirow[t]{2}{*}{ Types of amputations } & \multicolumn{3}{|l|}{ Types of DFSs } & \multirow[t]{2}{*}{$P$-value } & \multirow[t]{2}{*}{ Total, N (\% } \\
\hline & GDFS, $\mathbf{n}(\%)$ & UDFS, n (\%) & SDFS, n (\%) & & \\
\hline \multicolumn{6}{|l|}{ Toe amputations } \\
\hline No & $12(28.6)$ & $52(80.0)$ & $56(58.9)$ & 0.000 & $120(59.4)$ \\
\hline Yes & $30(71.4)$ & $13(20.0)$ & $39(4 I . I)$ & & $82(40.6)$ \\
\hline \multicolumn{6}{|l|}{ Minor amputations } \\
\hline No & $31(73.8)$ & $62(95.4)$ & $70(73.7)$ & 0.001 & $163(80.7)$ \\
\hline Yes & II (26.2) & $3(4.6)$ & $25(26.3)$ & & $39(19.3)$ \\
\hline \multicolumn{6}{|l|}{ Major amputations } \\
\hline No & $32(76.2)$ & $62(95.4)$ & $82(86.3)$ & 0.014 & $176(87.1)$ \\
\hline Yes & $10(23.8)$ & $3(4.6)$ & $13(13.7)$ & & $26(12.9)$ \\
\hline \multicolumn{6}{|c|}{ Major and minor amputations } \\
\hline No & $23(54.8)$ & $59(90.8)$ & $62(65.3)$ & 0.000 & I43 (70.8) \\
\hline Yes & $19(45.2)$ & $6(9.2)$ & $33(34.7)$ & & $58(29.2)$ \\
\hline
\end{tabular}

Abbreviations: DFS, diabetic foot syndrome; GDFS, gangrenous DFS; RCS-DFS, redefined clinical spectra of DFS; SDFS, septic DFS; UDFS, ulcerative DFS. 
tissue destruction and gangrene. ${ }^{14,19,31}$ Gangrene is a wellrecognized clinical problem of DF with poor outcome, ${ }^{10,16}$ and it is an independent predictor of amputations. ${ }^{32}$ Gangrene was reported in nearly $30 \%$ of hospitalized DFS. ${ }^{32,33}$ Gershater et $\mathrm{al}^{26}$ reported $6 \%$ of their large series to have Wagner's grade 4 (gangrene), which were excluded from the analysis related to lower extremity amputation, because gangrenous tissue ended up with some degree of amputation.

The prevalence of ulcers was $53.5 \%$, and the prevalence of infections was $72.3 \%$ in the study group. Ulcers were found in $45.3 \%$ of SDFS, Wagner's grade 3 ulcers were found in $54.7 \%$ of SDFS, while $13.7 \%$ were of grade 2 . Wagner's grade 2 ulcers were the majority of UDFS (87.6\%) while $12.4 \%$ were of grade 3 . Nearly $50 \%$ of UDFS and GDFS had mild infection. Therefore, Wagner's grade 0-2 ulcers might be infected, a finding that is supported by other studies where the prevalence and severity of DFIs increased with higher Wagner's grade. ${ }^{14,19,27}$ In a recent retrospective study, the healing of DF ulcer and overall outcome deteriorated with increasing severity of each subcategory of PEDIS classification system, with tendency for grades 1-2 to have mild infection and grade 3 to have moderate and severe infections. ${ }^{34}$ The prevalence of infections and its severity showed significant difference between RCS-DFS categories ( $P$-value $\leq 0.001$ ). Infected ulcer without ischemia (UT stage B) had elevenfold of increased risk of amputation compared to noninfected and non-ischemic ulcers (UT stage A) ${ }^{25}$ Furthermore, infections of DF ulcers were associated with an increased rate of minor amputations by $50 \%$ compared to noninfected ulcer. ${ }^{35}$ The rate of amputations increased from 3\% for noninfected ulcer to $70 \%$ for severely infected foot ulcers. ${ }^{36}$ Pickwell et $\mathrm{al}^{27}$ found an increased hazard for any amputation by a factor of 2.15 comparing moderate to mild infections, and the risk hazard for any amputation increased by a factor of 4.12 comparing severe to moderate infections. Gangrenous tissue might be infected as well. Wet gangrene with infections spreading to viable foot tissues (moderate and severe) carries high risk for poor outcome. ${ }^{23}$ Several studies demonstrated a strong association between amputation and higher problem severity (infection and gangrene). ${ }^{11,12,15,19,24,25,37}$ Previous studies, as well, demonstrated an increased rate of amputation, higher level of amputation and prolonged hospitalization in relation to increased severity of DFIs. ${ }^{18,37}$

Comparing the RCS-DFS in relation to amputation rate at all levels revealed significant difference. UDFS had the lowest amputation rate at all levels. SDFS and GDFS had comparable rate of minor amputations (21\%). On the other hand, GDFS had the highest rate at all levels except for minor amputations. Lower extremity amputation rates related to DFS showed global variations probably because of differences in study design and population, severities of DF problems, definition of amputations and the standard of care. .,9,26,35 $^{5}$

The RCS-DFS classification predicted amputations at all levels, and this might be due incorporation of a validated DFI classification system of IDSA/IWGDF. Results from validation studies of IDSA/IWGDF classification systems demonstrated an increase in amputation rate in association with increasing infection severity. ${ }^{18,27,36}$ On the other hand, validation of other classification systems for DF problems demonstrated variability in amputation predictions at different levels. ${ }^{11,25}$

In summary, DFS is a dynamic complex clinical foot problem in diabetic patients who have several clinical spectra at presentation. An ulcer can be the presenting clinical picture which might be due to neuropathy and ischemia, and it can be infected. ${ }^{4,6,38}$ Increased severity of infections is associated with poor outcomes. ${ }^{37}$ In community-based studies, nearly $50 \%$ of ulcers can be infected and the prevalence of infected ulcer might reach $82 \%$ for hospitalized DFS. Unhealed ulcer with/without mild infection, UDFS, can progress to higher grade of infection. This progression might be used as quality care indicator and an outcome parameter for UDFS management. Most of the UDFS cases and moderately infected ulcers without PAD cases can be treated as outpatients. ${ }^{15,18-20}$

The proportion and severity of pathogenic factors involved in the development of DFS can vary between patients and lesions (spectra).,39 Patients presenting with gangrene have distinct clinical picture, different underlying pathogenesis and different outcomes. Therefore, mixing gangrene with ulcers may lead to misunderstanding, confusion and diversity of reported outcome. None of the several proposed classification systems is satisfactory for all, ${ }^{11-13,17}$ neither it can cover all components in a clinically meaningful way. Therefore, the need for a clinical classification of DFS is well recognized. ${ }^{39}$ We proposed the RCS-DFS as a clinically useful classification tool that can predict amputations at all levels in relation to different spectra of DFS.

\section{Conclusion}

Redefining DFS into ulcerative, septic and gangrenous by integration of the predominant clinical presentation and the clinical criteria for DFI diagnosis and classification of IDSA/IWGDF showed significant differences in amputa- 
tion rate. Therefore, it can be used clinically to categorize patients with DFS to predict amputations and to help in planning their management. Further prospective studies are suggested to validate these results.

\section{Author contributions}

All the authors made substantial contributions to conception and design, acquisition of data or analysis and interpretation of data; contributed to drafting the article or revising it critically for important intellectual content approved the final version of the manuscript to be published; gave final approval of the version to be published; and agreed to be accountable for all aspects of the work in ensuring that questions related to the accuracy or integrity of any part of the work are appropriately investigated and resolved.

\section{Disclosure}

The authors report no conflicts of interest in this work.

\section{References}

1. Jeffcoate WJ, Harding KG. Diabetic foot ulcers. Lancet. 2003; 361(9368):1545-1551.

2. Rathur HM, Boulton AJ. The diabetic foot. Clin Dermatol. 2007;25(1): 109-120.

3. Malyar NM, Freisinger E, Meyborg M, et al. Amputations and mortality in in-hospital treated patients with peripheral artery disease and diabetic foot syndrome. J Diabetes Complications. 2016;30(6):1117-1122.

4. Reiber GE, Vileikyte L, Boyko EJ, et al. Causal pathways for incident lower-extremity ulcers in patients with diabetes from two settings. Diabetes Care. 1999;22(1):157-162.

5. Frykberg RG, Zgonis T, Armstrong DG, et al; American College of Foot and Ankle Surgeons. Diabetic foot disorders. A clinical practice guideline (2006 revision). J Foot Ankle Surg. 2006;45(5 Suppl): S1-S66.

6. Adler AI, Boyko EJ, Ahroni JH, Smith DG. Lower-extremity amputation in diabetes. The independent effects of peripheral vascular disease, sensory neuropathy, and foot ulcers. Diabetes Care. 1999;22(7):1029-1035.

7. Pscherer S, Dippel FW, Lauterbach S, Kostev K. Amputation rate and risk factors in type 2 patients with diabetic foot syndrome under real-life conditions in Germany. Prim Care Diabetes. 2012;6(3): 241-246.

8. Lavery LA, Armstrong DG, Wunderlich RP, Tredwell J, Boulton AJ. Diabetic Foot Syndrome: Evaluating the prevalence and incidence of foot pathology in Mexican Americans and non-Hispanic whites from a diabetes disease management cohort. Diabetes Care. 2003;26(5): $1435-1438$.

9. Jeffcoate WJ, Macfarlane RM, Fletcher EM. The description and classification of diabetic foot lesions. Diabet Med. 1993;10(7):676-679.

10. Wagner FW Jr. The dysvascular foot: a system for diagnosis and treatment. Foot Ankle. 1981;2(2):64-122.

11. Lavery LA, Armstrong DG, Harkless LB. Classification of diabetic foot wounds. J Foot Ankle Surg. 1996;35(6):528-531.

12. Armstrong DG, Lavery LA, Harkless LB. Validation of a diabetic wound classification system. The contribution of depth, infection, and ischemia to risk of amputation. Diabetes Care. 1998;21(5):855-859.

13. Schaper NC. Diabetic foot ulcer classification system for research purposes: a progress report on criteria for including patients in research studies. Diabetes Metab Res Rev. 2004;20 Suppl 1:S90-S95.
14. Lipisky BA, Berendt AR, Deery HG, et al; Infectious disease society of America. Diagnosis and treatment of diabetic foot infections. Clin Infec Dis. 2004;39(7):885-910.

15. Lipsky BA, Berendt AR, Cornia PB, et al; Infectious Diseases Society of America. 2012 Infectious Diseases Society of America clinical practice guideline for the diagnosis and treatment of diabetic foot infections. Clin Infect Dis. 2012;54(12):e132-e173.

16. Edmonds ME, Foster AVM. Management of Diabetic Foot. 2nd ed. Oxford: Blackwell Science; 2005.

17. Treece KA, Macfarlane RM, Pound N, Game FL, Jeffcoate WJ. Validation of a system of foot ulcer classification in diabetes mellitus. Diabet Med. 2004;21(9):987-991.

18. Wukich DK, Armstrong DG, Attinger CE, et al. Inpatient management of diabetic foot disorders: a clinical guide. Diabetes Care. 2013;36(9):2862-2871.

19. Prompers L, Huijberts M, Apelqvist J, et al. High prevalence of ischaemia, infection and serious comorbidity in patients with diabetic foot disease in Europe. Baseline results from the Eurodiale study. Diabetologia. 2007;50(1):18-25.

20. Alvarsson A, Sandgren B, Wendel C, Alvarsson M, Brismar K. A retrospective analysis of amputation rates in diabetic patients: can lower extremity amputations be further prevented? Cardiovasc Diabetol. 2012;11:18-29.

21. Nather A, Bee CS, Huak CY, et al. Epidemiology of diabetic foot problems and predictive factors for limb loss. J Diabetes Complications. 2008;22(2):77-82.

22. Mayfield JA, Reiber GE, Sanders LJ, Janisse D, Pogach LM. Association diabetes preventive foot care in diabetes. Diabetes Care. 2004;27:63-64.

23. Pecoraro RE, Reiber GE, Burgess EM. Pathways to diabetic limb amputation: basis for prevention. Diabetes Care. 1990;13(5):513-521.

24. Lavery LA, Armstrong DG, Wunderlich RP, Mohler MJ, Wendel CS, Lipsky BA. Risk factors for foot infections in individuals with diabetes. Diabetes Care. 2006;29(6):1288-1293.

25. Oyibo SO, Jude EB, Tarawneh I, Nguyen HC, Harkless LB. Boulton AJ. A comparison of two diabetic foot ulcer classification systems: the Wagner and the University of Texas wound classification systems. Diabetes Care. 2001;24(1):84-88.

26. Gershater MA, Löndahl M, Nyberg P, et al. Complexity of factors related to outcome of neuropathic and neuroischaemic/ischaemic diabetic foot ulcers: a cohort study. Diabetologia. 2009;52(3):398-407.

27. Pickwell K, Siersma V, Kars M, et al. Predictors of lower-extremity amputation in patients with an infected diabetic foot ulcer. Diabetes Care. 2015;38(5):852-857.

28. Gregg EW, Sorlie P, Paulose-Ram R, et al; 1999-2000 national health and nutrition examination survey. Prevalence of lower-extremity disease in the US adult population $>=40$ years of age with and without diabetes: 1999-2000 national health and nutrition examination survey. Diabetes Care. 2004;27(7):1591-1597.

29. Jude EB, Oyibo SO, Chalmers N, Boulton AJ. Peripheral arterial disease in diabetic and nondiabetic patients: a comparison of severity and outcome. Diabetes Care. 2001;24(8):1433-1437.

30. Miyajima S, Shirai A, Yamamoto S, Okada N, Matsushita T. Risk factors for major limb amputations in diabetic foot gangrene patients. Diabetes Res Clin Pract. 2006;71(3):272-279.

31. Bridges RM Jr, Deitch EA. Diabetic foot infections. Pathophysiology and treatment. Surg Clin North Am. 1994;74(3):537-555.

32. Pemayun TG, Naibaho RM, Novitasari D, Amin N, Minuljo TT. Risk factors for lower extremity amputation in patients with diabetic foot ulcers: a hospital-based case-control study. Diabet Foot Ankle. 2015;6:29629.

33. Bravo-Molina A, Linares-Palomino JP, Lozano-Alonso S, AsensioGarcía R, Ros-Díe E, Hernández-Quero J. Influence of wound scores and microbiology on the outcome of the diabetic foot syndrome. J Diabetes Complications. 2016;30(2):329-334.

34. Chuan F, Tang K, Jiang P, Zhou B, He X. Reliability and validity of the perfusion, extent, depth, infection and sensation (PEDIS) classification system and score in patients with diabetic foot ulcer. PLoS One. 2015;10(4):e0124739. 
35. van Battum P, Schaper N, Prompers L, et al. Differences in minor amputation rate in diabetic foot disease throughout Europe are in part explained by differences in disease severity at presentation. Diabet Med. 2011;28(2):199-205.

36. Lipsky BA, Weigelt JA, Sun X, Johannes RS, Derby KG, Tabak YP. Developing and validating a risk score for lower-extremity amputation in patients hospitalized for a diabetic foot infection. Diabetes Care. 2011;34(8):1695-1700.
37. Lavery LA, Armstrong DG, Murdoch DP, Peters EJG, Lipsky BA. Validation of the Infectious Diseases Society of America's Diabetic Foot Infection Classification System. Clin Infect Dis. 2007;44(4): $562-565$.

38. Boulton AJ. The diabetic foot: grand overview, epidemiology and pathogenesis. Diabetes Metab Res Rev. 2008;24 Suppl 1:S3-S6.

39. Game F. Classification of diabetic foot ulcers. Diabetes Metab Res Rev. 2016;32 Suppl 1:186-194.

\section{Publish your work in this journal}

Vascular Health and Risk Management is an international, peerreviewed journal of therapeutics and risk management, focusing on concise rapid reporting of clinical studies on the processes involved in the maintenance of vascular health; the monitoring, prevention and treatment of vascular disease and its sequelae; and the involvement of metabolic disorders, particularly diabetes. This journal is indexed on PubMed Central and MedLine. The manuscript management system is completely online and includes a very quick and fair peer-review system, which is all easy to use. Visit http://www.dovepress.com/ testimonials.php to read real quotes from published authors. 